\title{
BMJ Open Socioeconomic disparities in birth weight and body mass index during infancy through age 7 years: a study within the Danish National Birth Cohort
}

\author{
Camilla Schmidt Morgen, ${ }^{1,2}$ Per Kragh Andersen, ${ }^{3}$ Laust Hvas Mortensen, ${ }^{2}$ \\ Laura D Howe, ${ }^{4}$ Mette Rasmussen, Pernille Due, ${ }^{5}$ Thorkild I A Sørensen, ${ }^{1,4,6}$ \\ Anne-Marie Nybo Andersen ${ }^{2}$
}

To cite: Morgen CS, Andersen PK, Mortensen L H, et al. Socioeconomic disparities in birth weight and body mass index during infancy through age 7 years: a study within the Danish National Birth Cohort. BMJ Open 2017;7:e011781. doi:10.1136/bmjopen-2016011781

- Prepublication history and additional material is available. To view please visit the journal (http://dx.doi.org/ 10.1136/bmjopen-2016011781).

Received 4 March 2016 Revised 7 November 2016 Accepted 15 December 2016

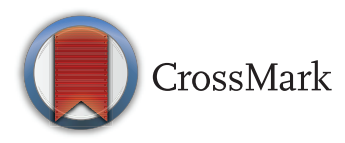

For numbered affiliations see end of article.

Correspondence to Dr Camilla Schmidt Morgen; Camilla@smorgen.dk

\section{ABSTRACT}

Background: Socioeconomic inequalities in birth weight and in body mass index (BMI) later in childhood are in opposite directions, which raises questions about when during childhood the change in direction happens. We examined how maternal and paternal education and household income were associated with birthweight z-scores and with BMI z-scores at age 5 and 12 months and 7 years, and we examined the socioeconomic differences in the tracking of these z-scores across infancy and childhood.

Methods: The associations were studied in a cohort of children in the Danish National Birth Cohort, single born between 1997 and 2003, for whom information on body size from at least 1 of 4 time points $(n=85062)$ was recorded. We examined the associations using linear mixed-effects modelling.

Results: Children from families with a low maternal and paternal educational level changed their body size z-scores upwards between birth and age 7 years. At age 5 and 12 months, there were no educational gradient. A low maternal educational level was associated with lower birth weight for gestational age z-scores at birth for boys $(-0.199 ; 95 \% \mathrm{Cl}-0.230$ to $-0.169)$ and girls $(-0.198 ; 95 \% \mathrm{Cl}-0.229$ to -0.167$)$ and higher BMI z-scores at age 7 for boys $(0.198$; $95 \% \mathrm{Cl} 0.154$ to 0.242$)$ and girls $(0.218 ; 95 \% \mathrm{Cl}$ 0.173 to 0.264 ). There was not a similarly clear pattern in the tracking between different household income groups. However, a low household income level was associated with higher z-scores of both birth weight and BMI at age 7 years, but with a much weaker gradient at 5 and 12 months.

Conclusions: The educational gradient shifts from positive with birth weight, to none during infancy to inverse with $\mathrm{BMI}$ at age 7 years. In contrast, the income gradient was positive at birth and at 7 years and much weaker during infancy.

\section{Strengths and limitations of this study}

- A strength of this study is the large sample size.

- Another strength is the repeated measures of body size and several indicators of socioeconomic position (parental education and household income).

- By linking the Danish National Birth Cohort (DNBC) to Statistics Denmark via the unique Danish personal identification number, it was possible to obtain information on socioeconomic indicators on almost all mothers participating in the DNBC.

- A limitation is the parental-reported measurements of height and weight at age 7 years.

- Another limitation is the selection for participation in the DNBC and for participation for follow-up, which could introduce bias.

\section{INTRODUCTION}

Childhood overweight and obesity pose a troubling threat to future public health. Although the increasing trends in childhood overweight and obesity seen in developed countries from the $1970 \mathrm{~s}^{1-4}$ have been followed by levelling off, ${ }^{5}{ }^{6}$ the prevalence has stabilised at a high level. Since childhood overweight and obesity track strongly into adulthood $^{7}$ with adverse health consequences, ${ }^{8}$ we need to trace the roots of the overweight epidemic by looking at explanatory factors as early in life as possible in order to develop effective prevention strategies. Children from less advantaged socioeconomic homes have traditionally had lower birth weight, ${ }^{9}$ but in high-income countries these children have an increased risk of 
overweight and obesity later in life. ${ }^{10-13}$ While there is evidence for an inverse relationship between socioeconomic position and body mass index (BMI) status among children, adolescents and adults, ${ }^{10-12}{ }^{14}$ these studies do not clearly indicate how early the socioeconomic inequalities in BMI and overweight emerge and how inequalities change and track across early childhood. Socioeconomic inequality in overweight among children has previously been addressed and found to be inconsistent, ${ }^{12}$ but in the recent cohorts, an increasing number of studies report an inverse socioeconomic gradient in child and adolescent overweight and obesity. ${ }^{14}$ However, studies with data from birth onwards yield very mixed results. ${ }^{15-20}$ Therefore, in a large Danish birth cohort, we aimed to investigate:

1. Whether individual changes in the tracking of anthropometry z-score from birth to age 7 years differ according to parental educational level and household income level at birth.

2. How maternal and paternal educational level and household income are associated with birth weight for gestational age z-scores and with BMI z-scores at age 5,12 months and 7 years.

We hypothesised that there would be socioeconomic inequalities in the tracking and that the socioeconomic gradient in the birthweight $\mathrm{z}$-score would be positive and that the gradient would shift during infancy and be inverse at age 7 years.

\section{MATERIALS AND METHODS}

Ethics statement: All participants in the Danish National Birth Cohort (DNBC) gave written informed consent. Data were analysed anonymously and the storage and linking of the data in this study were approved by the Danish Data Protection Agency and by the steering committee of the DNBC.

\section{Study population}

This study was based on data from the DNBC. Between 1996 and 2002, pregnant women in Denmark were invited to the cohort at their first antenatal visit to a general practitioner (GP). Women were eligible if they were able to complete a 30-40 min telephone interview in Danish. Approximately 30\% of all pregnant women in Denmark during the period of enrolment participated in the DNBC and the response rate among all invited women has been estimated to be $60 \%{ }^{21}$

The women provided information on exposures in four computer-assisted telephone interviews, in gestational weeks 16 and 31 and at child age 6 and 18 months. When the child turned 7 years of age, the parents were asked to fill in a questionnaire. A total of 100418 pregnancies were enrolled in the cohort. We initially included the 88181 live-born singleton children who were born at term. A total of 85062 of these had valid information on the exposure measures and at least one measurement of birth weight for gestational age or BMI at age 5, 12 months or
7 years and defined the study population (figure 1). More details about the cohort are presented elsewhere. ${ }^{21}$

\section{Measurement of outcomes}

Measurements of weight and length at birth were taken and registered by midwives and the information was obtained by linking the cohort with the Danish Medical Birth Registry. ${ }^{22}$ The GP takes routine measurements of height/length and weight at age 5 and 12 months. The measurements from these examinations are recorded in a 'child's book' which is kept by the parents and used for communication between the health visitors and the GP. In the telephone interview 18 months after the birth, the parents were asked to report the values from the 'child's book'. In the 7-year follow-up (mean follow-up was 7.1 years), the parents reported the latest measures of height and weight of the child. A total of $21 \%$ of the 7-year measurements were made by a GP or by a health visitor and the rest were made by the parents. The outcomes of interest were: birth weight for gestational age and BMI $z$-scores at age 5 months, 12 months and 7 years. Birthweight z-scores were calculated per gestational week at birth for boys and girls separately, and were based on the internal reference of 84782 newborn children. BMI z-scores were calculated using an internal reference value (z-score $=$ (observed value-mean)/SD) and were adjusted for exact age at the time of the measurement. For descriptive purposes (table 1), we categorised overweight according to the International Obesity Taskforce Reference (IOTF) ${ }^{23}$

\section{Measurement of exposures}

By linking the cohort participants to the Integrated Database for Labor Market Research at Statistics Denmark, ${ }^{24}$ we were able to collect information on the individual level of education and income for almost all participants in the cohort. The information was collected using 1st October in the year before childbirth as the time of exposure. Individual information on the longest completed education was categorised according to the International Standard Classification of Education system and converted into three groups: 9 years or less (preprimary, primary and lower secondary), 10-12 years (upper secondary, postsecondary) and 13 years or more (tertiary).

Income was measured as the taxable household income in the mother's household, calculated as the sum of the adults' income adjusted for the number of adults and children in the household uplifted to 0.6 to account for the "equivalence elasticity", the power by which economic needs change with household size (taxable household income/total number of residents in the household $\left.{ }^{0,6}\right) .^{25}$ We calculated income quintiles year by year (1996-2002) and summarised these into one measure.

\section{STATISTICAL ANALYSIS}

The associations were analysed using linear mixed-effects models calculating the differences 


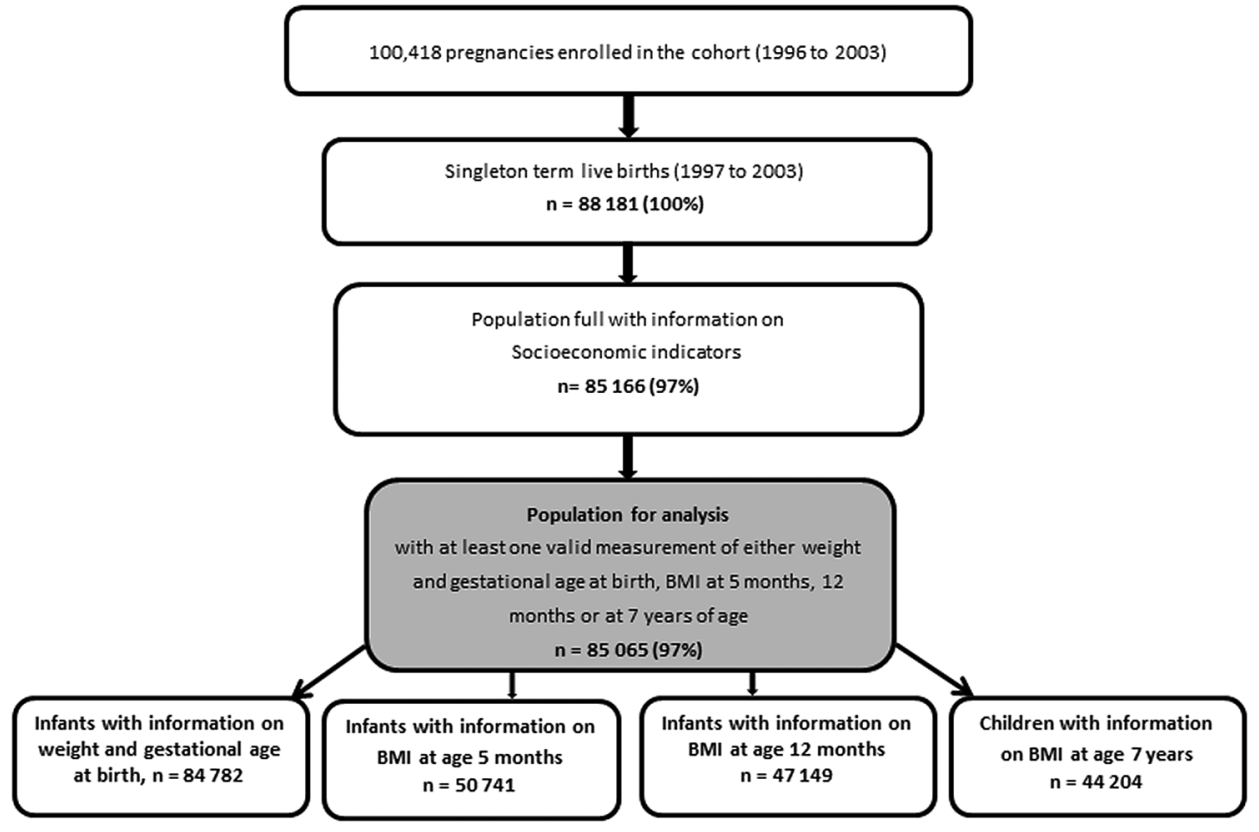

Figure 1 Flow chart showing the sampling in the study from the DNBC 1996-2010. BMI, body mass index; DNBC, Danish National Birth Cohort.

between mean birthweight z-scores and the differences between mean BMI z-scores with 95\% CIs. The linear mixed-effects model accounted for the intrachild correlation of the repeated BMI measurements by allowing all individuals to have different (random) intercepts. ${ }^{26}$ Allowing for an interaction between socioeconomic position and age allowed us to study body size changes over time (tracking) from birth to age 7 in different groups of socioeconomic position, as well as socioeconomic differences in birthweight and BMI z-scores at different ages. Different models were being fit for each measure of socioeconomic position. The models are explained in detail in online supplementary information S1. Given the gender differences documented in the literature on socioeconomic disparities in overweight and obesity, ${ }^{10} 15$ we decided, a priori, to stratify the analyses by sex. To test the robustness of our results, (1) we conducted the analyses with small for gestational age (SGA; below the 10th centile of the sex-specific and gestational agespecific birthweight distribution) as a measure of small size at birth instead of birth weight for gestational age, (2) we conducted the analyses with exclusion of mothers who were students and self-employed mothers.

We further examined the distribution of income by educational groups and education by income groups (see online supplementary table S2a and S2b).

\section{RESULTS}

\section{Sample characteristics}

A total of 85062 pregnancies with information on exposure measures and at least one measure of birth weight or child BMI were included in the analysis (figure 1). The average gestational age-specific birth weight and
BMI at age 5, 12 months and 7 years by parental socioeconomic indicator can be seen in table 1. Parental and child characteristics by parental socioeconomic indicator are presented in table 2. The percentages of overweight (including obese) among the 7-year-old children were greatest for the lowest educational and income groups (table 1). Women with low educational level were younger, had a younger partner, had more often given birth before, had a higher mean BMI, had partners with a higher BMI and were more often living in a singleparent household. The patterns were similar for paternal educational level and for families with a low relative household income (table 2).

Tracking of anthropometry over time according to parental socioeconomic position at birth

The tracking of BMI can be illustrated by setting the birthweight z-score as the reference. We compared the change in body size z-score from birth to age 7 years between educational groups and between income groups. We found that the changes in z-scores at age 7 years were positive for children with parents with $<12$ years of completed education, whereas the changes in $z$-scores were negative for children with parents with $>12$ years of completed education. By using the mean BMI and height for boys (BMI 15.7, SD 1.7, height $126.4 \mathrm{~cm}$ ) and girls (BMI 15.7, SD 1.8, height $125.4 \mathrm{~cm}$ ) in the cohort, the effect estimates can be translated into $\mathrm{kg}$ for illustration. Having a mother with low educational level was associated with a $0.5 \mathrm{~kg}$ higher weight for boys and a $0.6 \mathrm{~kg}$ higher weight for girls at age 7 years than if the children had followed their growth trajectory from birth. A high paternal educational level was associated 
ดิดิ

过

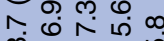

อิ

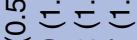

ำ

ल는ㄷㄴ

ใิธิ

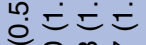

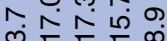

๖

นิกติ

L 5 등

이잉

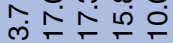

TRTK

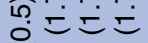

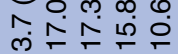

ใิด ฮิ

苟 $=$

众소송

\section{두ำ}

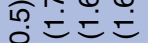

잉

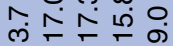

อิ

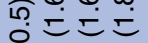

о लо

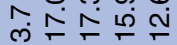

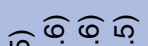

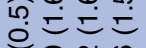

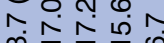

m

ธิดิ

등

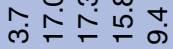

กิธต़

ก들

ํㅜㅇำ

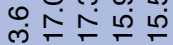

बढ़

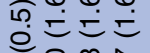

우수숭

的ㄷㄷㄴㅇ

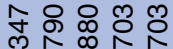

พำ Nㅗ N

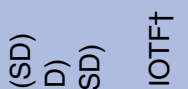

ठक्⿹

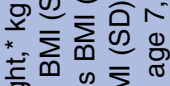

कू

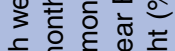

孚

ป

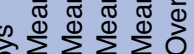

๑ิ

\begin{abstract}
(
\end{abstract}

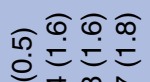$$
\text { ๑ }
$$

กิกิอ

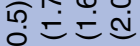

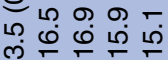

बढ़

นُ

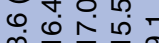

ิธติอ

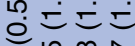

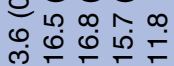

TกTKO

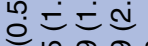

เก เด

மூ

ธิดิ

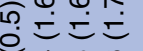

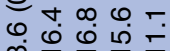

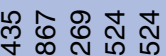

$\checkmark \stackrel{\sim}{N} \bar{N} \bar{N}$

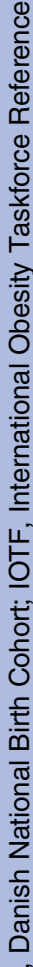

with a $0.6 \mathrm{~kg}$ lower weight for boys and a $0.4 \mathrm{~kg}$ lower weight for girls at age 7 years than if the children had followed their growth trajectory from birth.

The test for differences in tracking between groups showed that the differences in tracking in z-scores from birth to age 7 years were statistically significantly different between the educational groups, such that children born from parents in lower educational groups increased their body size z-scores more than did children from higher socioeconomic groups (all $\mathrm{p}$ values for the interaction between time and education were below 0.05 ; table 3 ). For household income, the changes in z-scores from birth to age 7 years were small and for most estimates not statistically significant. The test for differences in tracking between household income groups showed that tracking differed significantly, but there were no clear and consistent patterns in the tracking.

\section{Socioeconomic differences in birthweight z-scores and BMI z-scores at age 5, 12 months and 7 years}

Birth: For boys and girls, we found an association between low maternal and educational level and lower birthweight z-scores (figure 2 and online supplementary table S1). A household income below the highest quintile was associated with greater birthweight z-scores for boys and girls (table 4 ).

Age 5 and 12 months: We found no educational or income gradient in infancy BMI, indicating that the educational gradient shifted from positive to none and that the income gradient shifted from inverse to none in this age period. The estimates were mostly positive, but the majority of the CIs overlapped with the null and the tests for trends were not statistically significant, except for paternal educational level among girls aged 12 months and household income among boys aged 5 months (figure 2, table 4 and online supplementary table S1).

Age 7 years: Clear socioeconomic gradients in BMI z-scores were observed for all socioeconomic indicators such that a relatively low socioeconomic position, measured by education and income, was associated with higher BMI z-scores. Thus, the inverse socioeconomic gradient emerged after 12 months of age. For boys and girls with average BMI and height, the difference between lowest versus highest educational group can be translated into 0.5 and $0.6 \mathrm{~kg}$, respectively. Similar estimates were seen for paternal educational level. For boys and girls, the difference between lowest versus highest income groups can be translated into $0.4 \mathrm{~kg}$.

\section{Additional analyses testing the robustness of the results}

Additional analyses using SGA, appropriate and large for gestational age as the body size measures at birth showed the same tendencies as the analyses with birth weight for gestational age and BMI presented in the paper. Excluding mothers who were students or selfemployed did not change the results. 


\begin{tabular}{|c|c|c|c|c|c|c|c|c|c|c|c|c|}
\hline \multirow[b]{2}{*}{ Characteristics } & \multirow{2}{*}{$\begin{array}{l}\text { Total mean } \\
\text { or per cent }\end{array}$} & \multicolumn{3}{|c|}{ Maternal educational level (\%) } & \multicolumn{3}{|c|}{ Paternal educational level (\%) } & \multicolumn{5}{|c|}{ Household income (\%) } \\
\hline & & $<10$ years & 10-12 years & $>12$ years & $<10$ years & 10-12 years & $>12$ years & $<20$ & $20-<40$ & $40-<60$ & $60-<80$ & $80-100$ \\
\hline Total $n$ & & 10957 & 41667 & 32438 & 13827 & 44082 & 27153 & 16110 & 17129 & 17126 & 17335 & 17362 \\
\hline $\begin{array}{l}\text { Maternal mean } \\
\text { age }\end{array}$ & 29.2 & 27.2 & 28.7 & 30.6 & 28.0 & 28.8 & 30.5 & 28.4 & 29.0 & 29.1 & 29.2 & 30.4 \\
\hline (Range) & $(15-46)$ & $(15-46)$ & $(17-45)$ & $(21-46)$ & $(15-45)$ & $(15-46)$ & $(18-45)$ & $(15-46)$ & $(16-46)$ & $(17-45)$ & $(18-46)$ & $(18-46)$ \\
\hline $\begin{array}{l}\text { Paternal mean } \\
\text { age }\end{array}$ & 32.2 & 30.7 & 31.8 & 33.3 & 31.4 & 31.7 & 33.5 & 31.6 & 32.0 & 32.0 & 32.1 & 33.5 \\
\hline (Range) & $(16-71)$ & $(16-66)$ & $(17-71)$ & $(20-68)$ & $(16-66)$ & $(19-66)$ & $(22-71)$ & $(16-66)$ & $(17-67)$ & (19-63) & $(20-64)$ & $(20-71)$ \\
\hline Parity, 0 & 43.3 & 39.6 & 44.7 & 42.6 & 42.6 & 44.2 & 42.0 & 30.4 & 6.1 & 38.6 & 55.1 & 64.9 \\
\hline 1 & 50.9 & 53.1 & 50.0 & 51.6 & 50.8 & 50.2 & 52.1 & 62.3 & 68.0 & 56.8 & 39.7 & 29.0 \\
\hline Missing & 5.8 & 7.3 & 5.5 & 5.6 & 6.6 & 5.6 & 5.9 & 7.3 & 5.9 & 4.7 & 5.3 & 6.1 \\
\hline $\begin{array}{l}\text { Maternal mean } \\
\text { BMI }\end{array}$ & 23.6 & 24.3 & 23.8 & 23.0 & 24.5 & 23.8 & 22.8 & 23.8 & 24.0 & 23.9 & 23.5 & 22.8 \\
\hline (Range) & (13.9-57.8) & (13.9-57.8) & $(14.2-52.5)$ & $(13.9-55.5)$ & $(13.9-55.5)$ & $(13.9-57.8)$ & $(13.9-54.0)$ & (13.9-57.8) & $(14.2-55.5)$ & $(14.9-50.8)$ & (13.9-48.8) & (14.9-50.2) \\
\hline $\begin{array}{l}\text { Paternal mean } \\
\text { BMI }\end{array}$ & 25.2 & 25.6 & 25.3 & 24.8 & 25.7 & 25.3 & 24.7 & 25.3 & 25.3 & 25.2 & 25.1 & 24.9 \\
\hline (Range) & (14.9-57.9) & $(15.4-53.8)$ & $(14.9-57.8)$ & $(15.6-57.9)$ & (15.1-47.9) & $(14.9-57.9)$ & $(16.2-55.9)$ & $(15.4-55.6)$ & $(15.1-57.8)$ & $(14.9-55.9)$ & $(16.2-57.9)$ & $(15.6-54.1)$ \\
\hline $\begin{array}{l}\text { Single household } \\
\text { at } 18 \text { months }\end{array}$ & 2.1 & 4.8 & 2.1 & 1.3 & 4.4 & 2.1 & 1.1 & 4.4 & 2.2 & 1.8 & 1.4 & 1.0 \\
\hline \multicolumn{13}{|l|}{ Birth year } \\
\hline 1997 & 0.6 & 0.7 & 0.6 & 0.5 & 0.7 & 0.6 & 0.5 & 1.2 & 1.1 & 0.0 & 0.5 & 0.3 \\
\hline 1998 & 12.5 & 13.4 & 12.6 & 12.1 & 12.8 & 12.5 & 12.4 & 15.1 & 14.4 & 12.5 & 10.9 & 9.8 \\
\hline 1999 & 20.8 & 21.4 & 21.2 & 20.1 & 21.2 & 20.8 & 20.6 & 22.8 & 23.4 & 21.9 & 19.2 & 17.0 \\
\hline 2000 & 22.3 & 22.5 & 22.6 & 21.9 & 23.1 & 22.3 & 22.0 & 22.1 & 22.1 & 22.5 & 23.5 & 21.5 \\
\hline 2001 & 20.8 & 20.8 & 20.9 & 20.7 & 20.7 & 21.2 & 20.2 & 20.0 & 20.2 & 21.0 & 21.1 & 21.7 \\
\hline 2002 & 18.7 & 17.9 & 18.0 & 19.9 & 17.7 & 18.5 & 19.6 & 16.0 & 15.9 & 18.3 & 19.8 & 23.4 \\
\hline 2003 & 4.2 & 3.4 & 4.1 & 4.8 & 3.9 & 4.1 & 4.7 & 2.8 & 3.0 & 3.8 & 5.0 & 6.5 \\
\hline
\end{tabular}




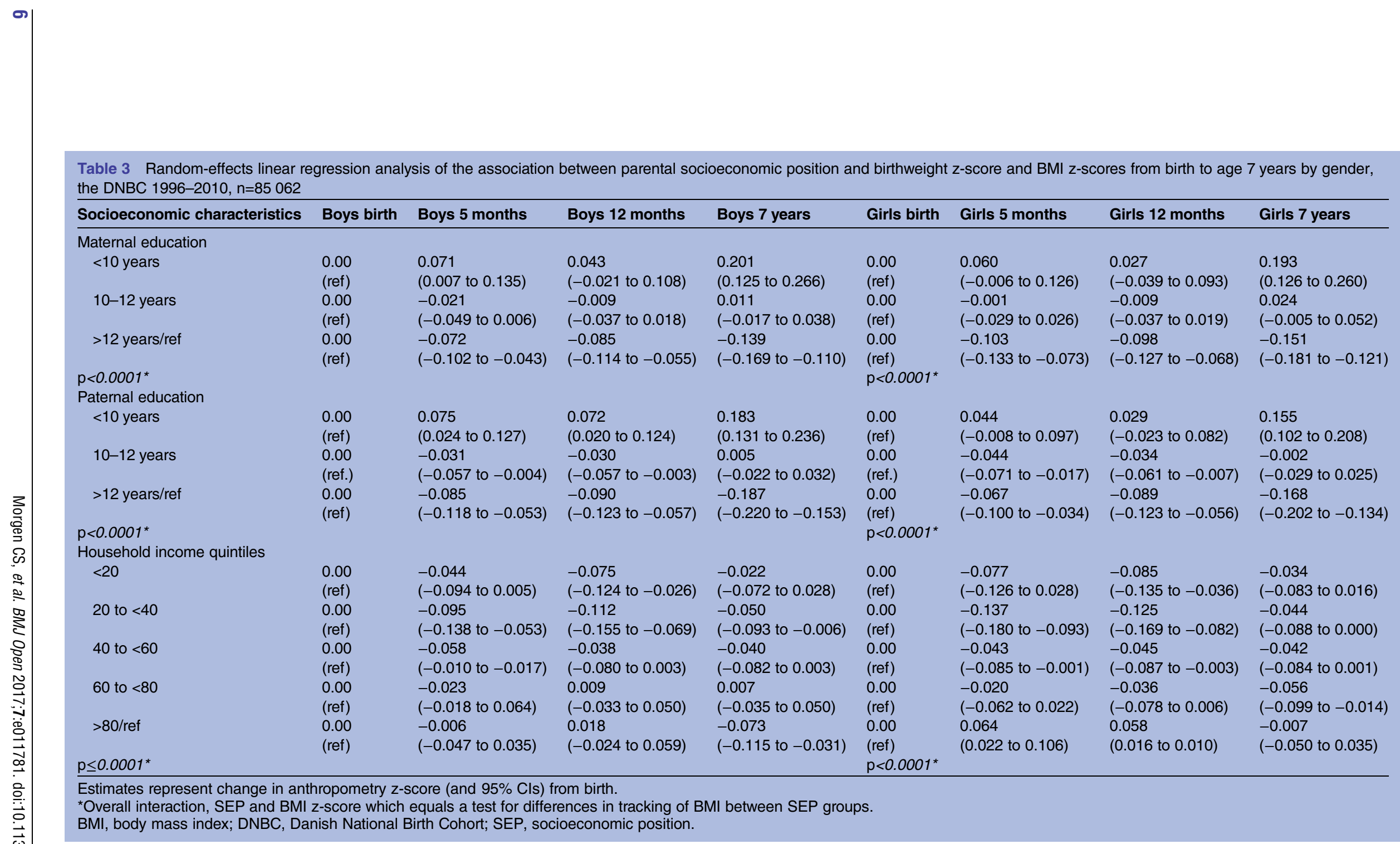

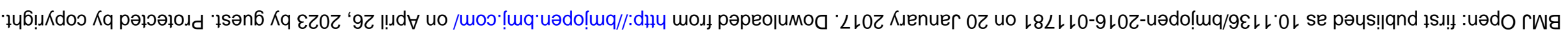



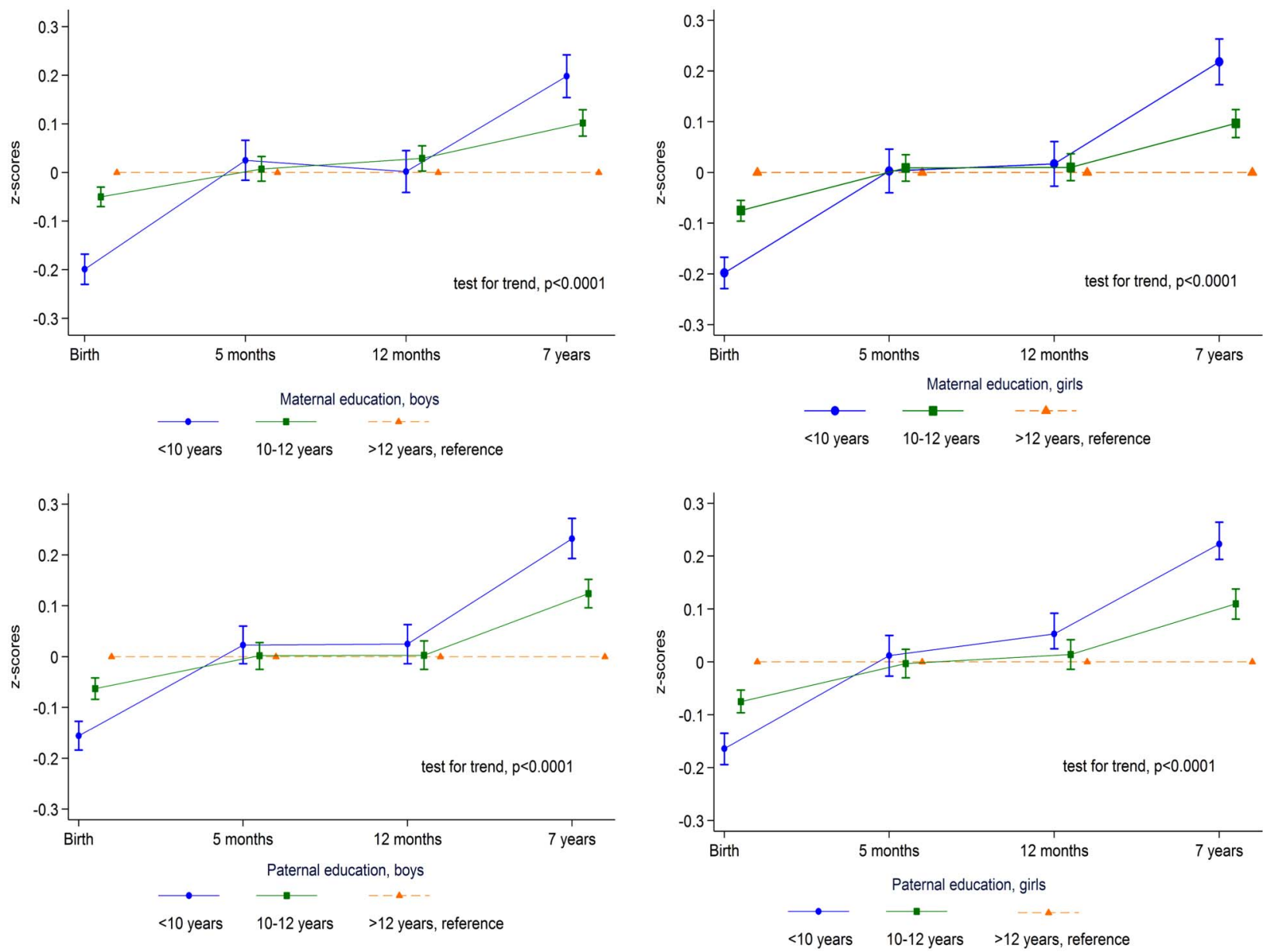

Figure 2 Random-effects linear regression analysis of the association between birthweight z-scores and BMl z-scores at age 5, 12 months and 7 years by maternal and paternal educational level at birth, the DNBC 1996-2010, $n=85062$. The estimates represent birth weight for gestational age z-scores and BMI z-scores with 95\% Cls. BMI, body mass index; DNBC, Danish National Birth Cohort.

By cross-tabulations and $\chi^{2}$ tests, we found that a high educational level was associated with high-income level and low educational level with a lower income level (see online supplementary table S2a and S2b).

\section{DISCUSSION}

This study showed that the change in body size from birth through age 7 years was socially patterned. A low educational level was associated with an increase in birth weight for gestational age z-score to BMI at age 7 years, whereas a high educational level was associated with a decrease in z-score in this period for both genders. Children with parents with a relatively low educational level were born with lower gestational age-specific birthweight z-scores and had higher BMI z-scores at age 7 years. For household income, the picture was different since a relatively low household income level was associated with higher birthweight z-scores and with higher BMI z-scores at age 7 years. We found that the socioeconomic gradient in BMI was not present during infancy for either education or income, indicating that the gradient disappears during the first few months of life and is established again after infancy, for parental educational level in inverse direction, and for income in the same direction as at birth.

Socioeconomic disparities are observed in highincome countries showing that lower socioeconomic position is associated with slightly more SGA births ${ }^{27}$ and higher overweight prevalence levels among children and adolescents. ${ }^{10} 13$ Children born with a high birth weight may represent a mixture of aetiologies: some children are high-risk children (eg, offspring of diabetic mothers) while others are low-risk children born with high birth weight for genetic and other non-detrimental reasons. ${ }^{9}$ This pattern may have changed with the obesity epidemic, whereby a larger proportion of children with high birth weight are born from overweight and obese mothers, and given the social patterning of adult obesity, the social patterning of birth weight may be in a period of change.

Education is an exposure, which may be viewed as a lifelong exposure and as a major route through which knowledge and privileges are passed from one generation to the other, and operates throughout the life course of the offspring. ${ }^{28}$ The educational level of the 


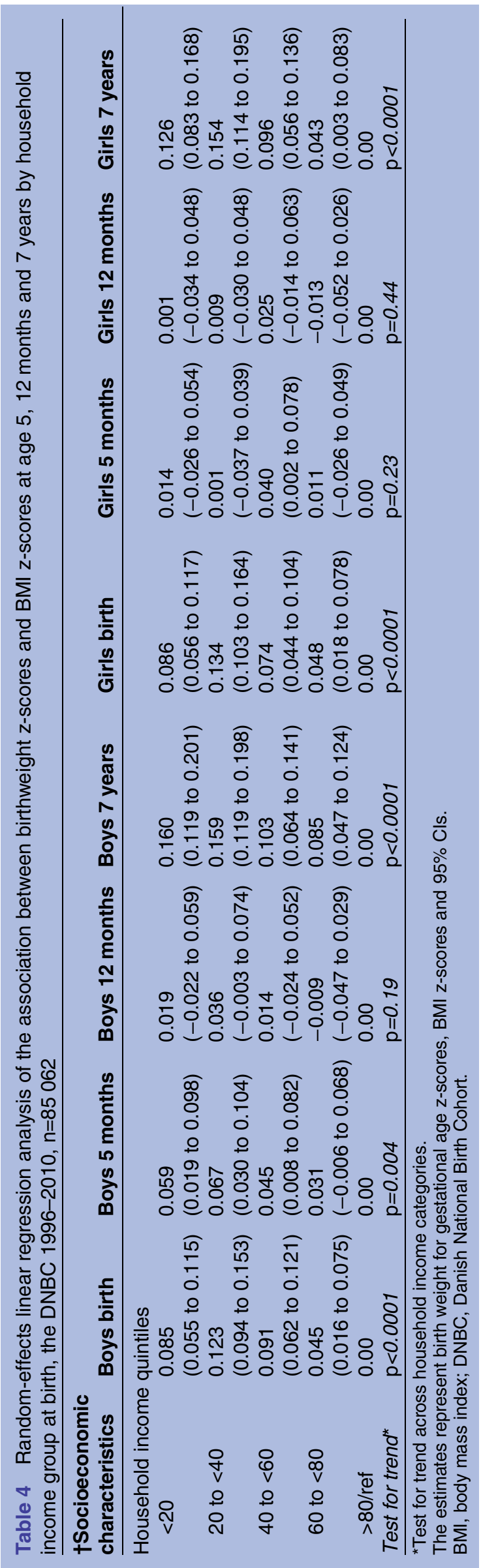

parents is assumed to reflect the intellectual resources of the family of origin, and hence the possible impact on health at an early age. Parental educational level is therefore considered suitable for measuring children's socioeconomic position already in early childhood. How parental education may operate and influence child body size during gestation and early childhood is an open question. The educational gradient in birth weight at term has been found to be partly explained by smoking and maternal pre-pregnancy BMI. ${ }^{29}$ A high parental educational level may lower the risk of overweight and affect BMI in children by a better incorporation of health education messages into the daily living and, consequently, healthier behavioural patterns; better skills to communicate with healthcare personnel; and a better access to healthcare services. Parental educational level may further affect the cognitive development of the child and thereby subsequent lifestyles. ${ }^{30}$

Household income is assumed to be a marker of material aspects of socioeconomic position. As for parental education, it is not clear how it may influence child body size. Income may affect birth weight and BMI in childhood through the conversion of money and assets to health-enhancing commodities and services. ${ }^{31}$ This could, for instance, be characterised by the possibility to choose to buy foods with low energy density and food with a greater diversity, which influences the food preferences and creates the basis for healthy food choices in childhood thereby passing habits from one generation to the next. ${ }^{32-35}$

Previous studies examining the social gradient in a longitudinal design with baseline at birth have shown mixed results regarding the timing of emergence of the socioeconomic gradient. ${ }^{15-20}$ Howe et al studied the socioeconomic pattering, measured by maternal education, in ponderal index and BMI trajectories within the Avon Longitudinal Study of Parents and Children (ALSPAC) with data from South-West England. They found no socioeconomic pattering in trajectories from age 0 to 2 years, but found that socioeconomic differences in BMI trajectories emerged at age 4 and widened between ages 4 and 10 years. ${ }^{15}$ These results correspond to the present study showing that the gradient emerges after infancy and in early childhood.

Dubois and Girard ${ }^{16}$ found no educational gradient in BMI at age 4.5 years, but they found increased odds of being at the 95th BMI centile or higher for children from the poorest families. Langnase et al concluded that the inverse socioeconomic gradient in BMI emerged between 2 and 6 years. Wijlaars $e t a l^{20}$ found no educational or occupational differences in birth weight, but an inverse socioeconomic gradient in weight already at age 3 months in twins. On the basis of the UK 1958 cohort, Power et $a l^{18}$ found an inverse socioeconomic gradient in obesity from age 16 years onwards, but not at younger ages. Our results are in line with those of Dubois and Langnase $e t a l,{ }^{17}$ but in contrast to those of Wijlaars et $a l,{ }^{20}$ which may be due to the different 
outcome measure and differences in associations between singletons and twins. The differences between our results and the results from the UK 1958 cohort $^{18}$ are possibly due to changes in the socioeconomic effects over time.

The finding of an inverse relation between household income and gestational age-specific birth weight was unexpected, since a previous Danish-Finnish study has shown a small but positive income-related inequality in SGA. ${ }^{27}$ To examine if many in the low-income group were students, we made analyses excluding this group. Additionally, we looked at the distribution of income by educational group. None of these factors could explain our findings. Our study may be a new development, but has to be tested in other populations before any conclusion is drawn.

Results from the previous studies addressing the question of whether there are socioeconomic differences in the 'tracking' of overweight across childhood indicate that children (age 7-10) from less advantaged socioeconomic backgrounds have an increased risk of overweight in adolescence. ${ }^{15} 36$ Our study adds to this literature by being based on a large sample size and by focusing on the tracking of body size z-scores from birth into childhood.

Overall, the differences between previous studies and the results from this study, at least in part, are likely to reflect that the risk factors for growth and increasing BMI, such as breast feeding, smoking during pregnancy and financial constraints on nutrition and physical activity, have different social distributions in different settings. ${ }^{37}$ The inverse socioeconomic gradient in childhood BMI and overweight is now present at earlier ages $^{15} 38$ and focusing on recent increased disparities during pregnancy, early life and early childhood may shed light on some of the mechanisms behind the development of overweight among younger children in the modern world. The next step from the analyses in the present paper will be to examine why we see these differences in the pathways between education and income on infant and child BMI. A recent systematic review highlights a significant gap in our mechanistic understanding of parent and child behaviours in relation to obesity among socioeconomically disadvantaged groups. $^{39}$

\section{STRENGTHS AND LIMITATIONS}

A strength of this study is its large sample size, and the availability of repeated measures of body size and multiple indicators of socioeconomic position. A possible limitation is the selection for participation in the cohort in general and for follow-up, which could introduce bias. Women of disadvantaged socioeconomic position are under-represented in the DNBC compared with the background population. ${ }^{40}$ The women participating in the 7-year follow-up have been found to be slightly older, less likely to be overweight before pregnancy and less likely to smoke during pregnancy than those lost to follow-up. ${ }^{41}$ Also, there was a slightly lower percentage of overweight children at age 7 years in the cohort than in the general Danish population. ${ }^{42}$ The socioeconomic measures and birthweight measure have the advantage of being collected from the registers, so that neither of the measures relies on self-reports. The measures of length and weight at 5 months of age have the advantage of being measured routinely by the GP, but all measurements are individual measurements and may be subject to measurement error. However, the possible misclassification is most likely non-differential. The parents reported height and weight at age 7 years and self-reporting often leads to an under-reporting of BMI. ${ }^{43}$ A possible underestimation might have been socially skewed. ${ }^{45}$ If the socioeconomically disadvantaged parents tended to under-report children's BMI more than the socioeconomically advantaged ones, this would have affected the socioeconomic associations with child BMI at age 7 years towards the null. The reported measurements at age 7 years have been compared with measures of height and weight in a subsample of 1122 children measured by a school doctor. This validation showed that the percentage of children categorised as overweight was slightly lower in the DNBC compared with the school doctors' measurements. However, the validation showed no trend towards increasing differences of weight or height with increasing averages of weight or height between the measurements from school doctors and from the DNBC, most likely reflecting that the disagreements are random errors. ${ }^{46}$

Previous studies have addressed the relatively low participation rate and the loss to follow-up in the DNBC. ${ }^{40} 4147$ Different associations were examined and the authors concluded that the internal comparisons were robust to the lack of representativeness, and that the bias due to loss to follow-up was small. ${ }^{41}{ }^{47}$ Howe et $a l^{48}$ have examined how loss to follow-up in cohort studies often resulted in underestimation of the socioeconomic inequalities, but they found that the direction and the approximate magnitude of the examined associations were valid. Loss to follow-up and self-reported BMI at age 7 years may have affected the 7 -year estimates towards the null, but we have no reason to believe that the answer to the main research question in our studyregarding the change of the socioeconomic gradient in child body size-should be biased due to these weaknesses.

Our study was based on one assessment of socioeconomic position before delivery, which allowed us to keep a temporal sequence between exposure and outcomes at birth and in infancy. However, socioeconomic position may change over time, and future studies may address the influence of possible changes in various aspects of parental socioeconomic indicators on BMI later in childhood. 


\section{CONCLUSIONS}

In this study, we found that children from families with a lower educational level increased their body size z-score from birth to age 7 years, whereas children from families with a higher educational level decreased the z-scores in this 7-year period. We found an association between a lower maternal and paternal educational attainment and lower birth weight for gestational age z-scores and higher BMI z-scores at age 7 years. We found an unexpected association between a lower household income level and higher birth weight for gestational age z-scores, but an expected association with higher 7-year BMI z-scores. We found no educational gradient or household income gradient in infancy. The results indicate that the socioeconomic gradient in body size z-scores disappears during the first months of life and then it develops for parental education in inverse direction and for household income in the same direction after infancy.

\section{Author affiliations}

${ }^{1}$ Department of Clinical Epidemiology (formerly Institute of Preventive Medicine), Copenhagen, Denmark

${ }^{2}$ Section of Social Medicine, Department of Public Health, University of Copenhagen, Copenhagen, Denmark

${ }^{3}$ Section of Biostatistics, Department of Public Health, University of Copenhagen, Copenhagen, Denmark

${ }^{4} \mathrm{MRC}$ Integrative Epidemiology Unit, The University of Bristol, and School of Social and Community Medicine, University of Bristol, Bristol, UK ${ }^{5}$ National Institute of Public Health, University of Southern Denmark, Copenhagen, Denmark

${ }^{6}$ Faculty of Health and Medical Sciences, Novo Nordisk Foundation Center for Basic Metabolic Research and Department of Public Health, University of Copenhagen, Copenhagen, Denmark

Contributors CSM and A-MNA conceived the study. PKA, LDH, LHM and CSM planned the analyses; CSM prepared the data set for analysis and conducted the data analyses by supervision of PKA. CSM, A-MNA, PKA, TIAS LHM, LDH, MR and PD interpreted the results; CSM prepared the manuscript; A-MNA, PKA, TIAS, LHM, LDH, MR and PD critically revised the manuscript; and TIAS and A-MNA participated in the planning and building of the DNBC. CSM have the responsibility for the final content. All authors read and approved the final manuscript.

Funding The work is supported by the research programme 'Governing Obesity' funded by the University of Copenhagen Excellence Programme for Interdisciplinary Research (http://www.go.ku.dk). This work has further been supported by the University of Copenhagen, Danish Graduate School of Health and Medical Sciences, and by a donation from the Health Foundation (2008B121). LDH is supported by a UK Medical Research Council Population Health Scientist Fellowship (G1002375). The Danish National Research Foundation has established the Danish Epidemiology Science Centre that initiated and created the Danish National Birth Cohort (DNBC). The cohort is furthermore a result of a major grant from this Foundation. Additional support for the DNBC is obtained from the Pharmacy Foundation, the Egmont Foundation, the March of Dimes Birth Defects Foundation, the Augustinus Foundation and the Health Foundation. The DNBC 7-year follow-up is supported by the Lundbeck Foundation (195/04) and the Danish Medical Research Council (SSVF 0646).

\section{Competing interests None declared.}

Patient consent Obtained.

Ethics approval The Danish National Committee on Biomedical Research Ethics approved the collection of data.

Provenance and peer review Not commissioned; externally peer reviewed.

Data sharing statement Data are available by application from the DNBC. http://www.ssi.dk/Forskning/Forskningsomraader/Epidemiologi/BSMB/onsker\%
20du\%20at\%20forske/Hvordan\%20soge\%20om\%20data.aspx. Additional data are available by application to the DNBC

Open Access This is an Open Access article distributed in accordance with the Creative Commons Attribution Non Commercial (CC BY-NC 4.0) license, which permits others to distribute, remix, adapt, build upon this work noncommercially, and license their derivative works on different terms, provided the original work is properly cited and the use is non-commercial. See: http:// creativecommons.org/licenses/by-nc/4.0/

\section{REFERENCES}

1. Due P, Heitmann BL, Sørensen TIA. Prevalence of obesity in Denmark. Obes Rev 2007;8:187-9.

2. Lissau I, Overpeck MD, Ruan WJ, et al. Body mass index and overweight in adolescents in 13 European countries, Israel, and the United States. Arch Pediatr Adolesc Med 2004;158:27-33.

3. Lobstein T, Baur L, Uauy R. Obesity in children and young people: a crisis in public health. Obes Rev 2004:5(Suppl 1):4-104.

4. Ogden CL, Carroll MD, Lawman HG, et al. Trends in obesity prevalence among children and adolescents in the United States, 1988-1994 through 2013-2014. JAMA 2016;315:2292-9.

5. Morgen CS, Rokholm B, Brixval CS, et al. Trends in prevalence of overweight and obesity in Danish infants, children and adolescents —are we still on a plateau? PLOS ONE 2013;8:e69860.

6. Rokholm B, Baker JL, Sørensen TIA. The levelling off of the obesity epidemic since the year 1999-a review of evidence and perspectives. Obes Rev 2010;11:835-46.

7. Whitaker RC, Wright JA, Pepe MS, et al. Predicting obesity in young adulthood from childhood and parental obesity. $N$ Engl J Med 1997;337:869-73.

8. Reilly JJ, Kelly J. Long-term impact of overweight and obesity in childhood and adolescence on morbidity and premature mortality in adulthood: systematic review. Int J Obesity 2011;35:891-8.

9. Mortensen LH, Nybo AM. Social inequality in birth weight. A NORdic comparative and collaborative study of the development 1980-2005. Eur J Epidemiol 2006;21:146.

10. Due P, Damsgaard MT, Rasmussen M, et al. Socioeconomic position, macroeconomic environment and overweight among adolescents in 35 countries. Int J Obesity 2009;33:1084-93.

11. Knai C, Lobstein T, Darmon N, et al. Socioeconomic patterning of childhood overweight status in Europe. Int $J$ Environ Res Public Health 2012;9:1472-89.

12. Sobal J, Stunkard AJ. Socioeconomic-status and obesity: a review of the literature. Psychol Bull 1989;105:260-75.

13. Shrewsbury V, Wardle J. Socioeconomic status and adiposity in childhood: a systematic review of cross-sectional studies 19902005. Obesity 2008;16:275-84.

14. Barriuso L, Miqueleiz E, Albaladejo R, et al. Socioeconomic position and childhood-adolescent weight status in rich countries: a systematic review, 1990-2013. BMC Pediatr 2015;15:129.

15. Howe LD, Tilling K, Galobardes B, et al. Socioeconomic disparities in trajectories of adiposity across childhood. Int $J$ Ped Obesity 2011;6:E144-53.

16. Dubois L, Girard M. Early determinants of overweight at 4.5 years in a population-based longitudinal study. Int J Obes 2006;30:610-17.

17. Langnase $\mathrm{K}$, Mast M, Danielzik S, et al. Socioeconomic gradients in body weight of German children reverse direction between the ages of 2 and 6 years. J Nutr 2003;133:789-96.

18. Power $\mathrm{C}$, Manor O, Matthews S. Child to adult socioeconomic conditions and obesity in a national cohort. Int $J$ Obes 2003;27:1081-6.

19. Strauss RS, Knight J. Influence of the home environment on the development of obesity in children. Pediatrics 1999;103:6-14.

20. Wijlaars LPMM, Johnson L, van Jaarsveld CHM, et al. Socioeconomic status and weight gain in early infancy. Int $J$ Obes 2011;35:963-70.

21. Olsen J, Melbye M, Olsen SF, et al. The Danish National Birth Cohort-its background, structure and aim. Scand J Public Health 2001:29:300-7.

22. Knudsen LB, Olsen J. The Danish Medical Birth Registry. Dan Med Bull 1998;45:320-3.

23. Cole TJ, Bellizzi MC, Flegal KM, et al. Establishing a standard definition for child overweight and obesity worldwide: international survey. BMJ 2000;320:1240-3.

24. Jensen VM, Rasmussen AW. Danish education registers. Scand J Public Health 2011;39(7 Suppl):91-4.

25. OECD modified scale. http://www.oecd.org/eco/growth/ OECD-Note-EquivalenceScales.pdf 011 (accessed Dec 2015). 
26. Diggle PJ, Heagerty PJ, Liang KY, et al. Analysis of longitudinal data. New York: Oxford University Press, 2002:54-113.

27. Mortensen LH, Lauridsen JT, Diderichsen F, et al. Income-related and educational inequality in small-for-gestational age and preterm birth in Denmark and Finland 1987-2003. Scand J Public Health 2010;38:40-5.

28. Due $\mathrm{P}$, Krolner R, Rasmussen M, et al. Pathways and mechanisms in adolescence contribute to adult health inequalities. Scand J Public Health 2011;39:62-78.

29. Mortensen LH, Nybo AM. The social gradient in birthweight at term: quantification of the mediating role of maternal smoking and body mass index. Hum Reprod 2009;10:2629-35.

30. Power C, Kuh D, Morton S. From developmental origins of adult disease to life course research on adult disease and aging: insights from birth cohort studies. Annu Rev Public Health 2013;34:7-28.

31. Galobardes B, Shaw M, Lawlor DA, et al. Indicators of socioeconomic position (part 2). J Epidemiol Community Health 2006;60:95-101.

32. Drewnowski A. Obesity and the food environment: dietary energy density and diet costs. Am J Prev Med 2004;27:154-62.

33. Drewnowski A, Darmon N, Briend A. Replacing fats and sweets with vegetables and fruits-a question of cost. Am J Public Health 2004;94:1555-9.

34. Galobardes B, Shaw M, Lawlor DA, et al. Indicators of socioeconomic position (part 1). J Epidemiol Community Health 2006;60:7-12.

35. Kuh D, Power C, Blane D, et al. Social pathways between childhood and adult health. In: Kuh D, Ben-Shlomo A, eds. A life course approach to chronic disease. Oxford: Oxford University Press, 2013:169-78.

36. Kristensen PL, Wedderkopp N, Møller NC, et al. Tracking and prevalence of cardiovascular disease risk factors across socio-economic classes: a longitudinal substudy of the European Youth Heart Study. BMC Public Health 2006;6:20-9.

37. Monasta L, Batty GD, Cattaneo A, et al. Early-life determinants of overweight and obesity: a review of systematic reviews. Obes Rev 2010;11:695-708.
38. Pinot de MA, Power C, Li L. Changing influences on childhood obesity: a study of 2 generations of the 1958 British birth cohort. Am J Epidemiol 2010;171:1289-98.

39. Russel CG, Taki S, Laws R, et al. Effects of parent and child behaviours on overweight and obesity in infants and young children from disadvantaged backgrounds: systematic review with narrative synthesis. BMC Public Health 2016;16:151.

40. Jacobsen TN, Nøhr EA, Frydenberg M. Selection by socioeconomic factors into the Danish National Birth Cohort. Eur J Epidemiol 2010;25:349-55.

41. Greene N, Greenland S, Olsen J, et al. Estimating bias from loss to follow-up in the Danish National Birth Cohort. Epidemiology 2011;22:815-22.

42. Pearson S, Hansen B, Sørensen $\mathrm{TI}$, et al. Overweight and obesity trends in Copenhagen schoolchildren from 2002 to 2007. Acta Paediatr 2010;99:1675-8.

43. Elgar FJ, Roberts C, Tudor-Smith $C$, et al. Validity of self-reported height and weight and predictors of bias in adolescents. J Adolesc Health 2005;37:371-5.

44. Goodman E, Hinden BR, Khandelwal S. Accuracy of teen and parental reports of obesity and body mass index. Pediatrics 2000;106:52-8.

45. Himes $\mathrm{JH}$, Hannan $\mathrm{P}$, Wall $\mathrm{M}$, et al. Factors associated with errors in self-reports of stature, weight, and body mass index in Minnesota adolescents. Ann Epidemiol 2005;15:272-8.

46. Andersen CS. Validation of the height, weight and waist circumference in the 7-year follow-up in the Danish National Birth Cohort. http://www.ssi.dk/English/RandD/Research\% 20areas/Epidemiology/DNBC/Publications\%20on\% 20Background\%20and\%20Methods/Validation\%20of\%20height \%20weight\%20and\%20waist\%20circumference.aspx (accessed 18 Dec 2015).

47. Nøhr EA, Frydenberg M, Henriksen TB, et al. Does low participation in cohort studies induce bias? Epidemiology 2006;17:413-18.

48. Howe LD, Tilling K, Galobardes B, et al. Loss to follow-up in cohort studies bias in estimates of socioeconomic inequalities. Epidemiology 2013;24:1-9. 